\title{
Terremotos y salud psicosocial
}

Los terremotos y los continuos movimientos telúricos que han azolado al país a lo largo de los primeros meses del presente año no sólo han puesto al descubierto nuevamente la vulnerabilidad socioambiental de El Salvador, sino que además han revelado la precariedad de las condiciones de subsistencia de la mayoría de la población salvadoreña, sobre lodo la de aquella que vive en el campo y que aún no goza del progreso y del desarrollo largamente prometidos. Una de esas condiciones que más se agudizó con la ocurrencia de los terremotos y la persistencia de la actividad sísmica fue, sin duda, la salud mental o salud psicosocial' de los salvadoreños.

Los terremotos implicaron no sólo la pérdida inesperada de familiares cercanos, la destrucción física del hábital y de los medios de subsistencia de mucha gente - con lo cual se han abierlo heridas y generado mucho dolor que, luego de tres meses, no ha dejado de dominar los sentimientos de los afectados-, sino que además, y en un sentido más psicológico, constituyeron el resquebrajamiento absoluto del precario equilibrio que mantenía la gente con su medio ambiente social. Los terremolos y, sobre todo, la persistente actividad sísmica destruyeron el orden $\longrightarrow$ desorden- psicosocial construido por los ciudadanos para subsistir en un ambiente de suyo muy precario. La sensación de absoluta indefensión y de la falta de herramientas para anticipar y evitar el posible daño provocado por el probable siguiente movimiento telúrico, frente a la necesidad de recuperar la normalidad y cumplir con las tareas vitales básicas, desestructuró los mecanismos habituales de defensa de la gente y la sumergió en una serie de síndromes que se sumaron a los habituales síntomas provocados por lo que Ignacio Martín-Baró dio en llamar el "permanente estado de emergencia vital". La sensación de la falta de control sobre el contexto inmediato, de suyo precario, se convirtió en la regla general durante varias semanas. $\mathrm{La}$ incertidumbre se constituyó en la pauta predominante del comportamiento y la incapacidad para afrontar los conflictos más triviales y nimios en la vida colidiana agravó la relación de muchos ciudadanos para con su medio ambiente.

En una visila realizada a una de las tantas comunidades rurales devastadas por el terremoto en el departamento de Cuscatlán, tuvimos la oportunidad de acompañar el proceso de atención de consulta médica facilitado por la radio YSUCA, a través de un médico voluntario de la comunidad de radiohablantes. Más del 65 por ciento de las consultas médicás atendidas en los adultos - por las cuales pasó práclicamente toda la comunidad ahí reunida, especialmente los niños- eslaban generadas o acompañadas por trastornos vinculados a aspectos psicológicos. Los trastornos de carácter aparentemente psicológico formaban parte del grupo de las primeras tres o cuatro causas de consulta, inclusive en niños, a partir de los siete u ocho años. Aun en aquellos casos en los cuales la gente consultaba por síntomas como diarreas, problemas respiratorios, alergias en la piel y otros, la consulta era aprovechada para exponer los problemas de ansiedad y angustia, insomnio, "temblores en el

1. Más allá de las diferencias conceptuales, en esic comentario se usarán ambas terminologias como sinónimos. 


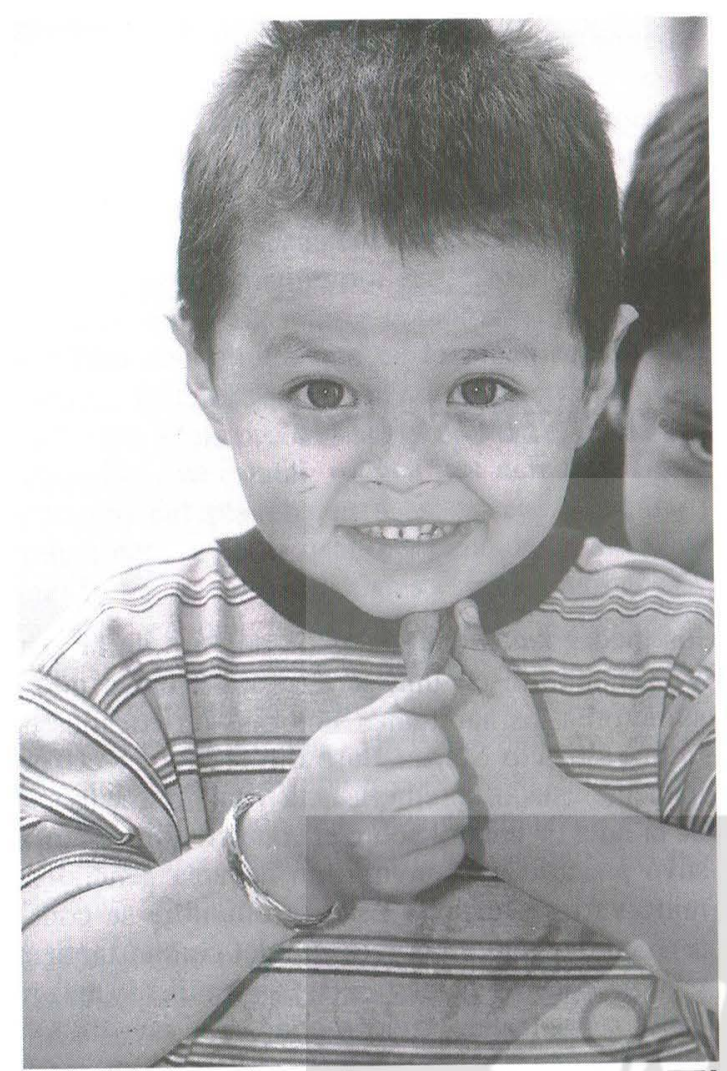

cuerpo", "ganas de gritar y salir corriendo", dolores de cabeza, etc.

Muy revelador fue encontrar que varias personas tenían esos síntomas desde antes de los terremolos y éstos no hicieron más que agravarlos considerablemente. En esos casos, el desastre natural sólo había exacerbado las reacciones psicológicas, producidas por el desastre social, en el que viven muchas de estas personas. Comunidades cuya nota predominante es la pobreza y la ausencia de recursos, debían lidiar desde antes del terremolo con las carencias y las dinámicas de alteraciones psicosociales producidas, en parte, por aquéllas. Por ejemplo, una señora de alrededor de 50 años de edad se quejaba de problemas de angustia y tristeza. Tales síntomas existian desde antes de los terremolos y parecían estar vinculados a problemas familiares: seis hijos - todos adultos-y un marido con problemas de alcoholismo, de lal forma que el único sostén económico regular del hogar era ella; el terremoto mató a algunos de sus nietos y provocó que sus familiares hombres se hundieran más en la adicción alcohólica ("algunos des- pués del terremoto agarraron 'zumba'”). En otros casos, los terremotos habían agudizado los conflictos de interacción social comunitaria, agravando con ello la sensación de inseguridad personal dentro de la comunidad. Otra señora se quejaba de fuertes y frecuentes dolores de cabeza. Cuando se le preguntó por las razones de los mismos, afirmó que pensaba mucho en un conflicto de límites de propiedad con una vecina, el cual se había agravado luego de los terremotos, al aumentar el valor de las propiedades que habían quedado de pie.

Estos casos sugieren que el problema de la salud mental entre muchos de los ciudadanos no surge con los terremotos, sino que se vuelven más evidentes. No se trata de ciudadanos que estaban bien antes del terremolo y que la catástrofe los convirtió en víctimas; se trata de ciudadanos que tienen una larga historia de victimización por sus propias condiciones de vida, por desastres anteriores y por la falta de eficacia institucional para atender sus necesidades más básicas. Los siniestros de enero y febrero dejaron ver también cómo la vida de muchos ciudadanos está, además, marcada por los desastres. Un anciano con no menos de 70 años de edad, quien consultaba por un dolor insistente en la cadera, respondió a la pregunta sobre su edad de la siguiente forma: "Mire, no lo sé. Sólo me acuerdo que cuando estaba pequeño hubo un gran ciclón que mató a mucha gente y que inundó adonde yo vivía. Y eso fue hace muchos años. Desde entonces vivo yo". La memoria de muchos ciudadanos, sobre todo de aquellos más pobres, es un recuento de desgracias, tanto naturales como sociales, tanto ecológicas como humanas. Y esta es una dimensión que debe tomarse en cuenta a la hora de diseñar los planes de atención en salud mental.

La ingente necesidad de atención en salud psicosocial de las comunidades destrozadas por el terremolo es producto de las condiciones de vida en que los ciudadanos han debido sobrevivir durante años, y no sólo es producto del impacto circunstancial del desastre natural. Sin duda, el siniestro provocó muchas tragedias difíciles de anticipar o, inclusive, de prevenir; pero el mayor impacto se debió a las condiciones extremas de vulnerabilidad y de perenne emergencia en la que deben vivir los salvadoreños más pobres. Acostumbrados a preocuparse por la alimentación diaria y el vestido más o menos digno, de la noche a la mañana, miles de ciudadanos se enfrentaron al hecho de no tener un lugar seguro donde vivir, de no 
tener los recursos básicos de subsistencia y, en algunos casos, de no contar con el apoyo de otros miembros de la familia, porque estaban muertos. La tragedia desbarató, por tanto, el precario equilibrio de la subsistencia y dejó abierta la posibilidad para una catástrofe mayor en la conciencia de la gente. Esto ha agravado la también precaria salud mental de la población. De ahí que el impacto del terremoto no sólo deba medirse en términos físicos o materiales, sino también psicosociales, en términos de la incidencia que han tenido en un contexto de por sí calamitoso.

La cuestión es que muchos ciudadanos del interior del país no sólo perdieron a sus familiares, sus trabajos y sus viviendas sino que, además, y por el carácter de la misma, extraviaron un marco de referencia racional y emocional, que diera sentido a una tragedia superpuesta a las tragedias cotidianas de la subsistencia. A diferencia de los desastres provocados por el hombre, en donde puede ser más fácil buscar responsables, encontrar un sentido e idealizar la tragedia (por ejemplo, las muertes en la guerra), los terremotos poseían una dimensión de inevitabilidad y de fatalidad azarosa, que difícilmente encajaba en los marcos racionales de explicación de la gente. Ello dio más espacio a las explicaciones mágicas y religiosas aumentando con ello el sentido de fatalismo que ya reina en muchos hogares salvadoreños, sobre todo en los más pobres y más precarios socialmente. Explicaciones enfocadas en la voluntad divina, ya sea como parte de un profecía biblica o como castigo de Dios frente a los desmanes de las propias conductas o las de otros, inundaron las pláticas comunilarias, los medios de comunicación y las consultas con especialistas. Esto fue estimulado además por predicadores o grupos fundamentalistas, quienes aprovecharon la incertidumbre provocada por la tragedia para diseminar su mensaje apocalíptico, a través de los medios de comunicación o inclusive a través de seudocampañas de asistencia psicológica, en los campamentos de damnificados por los sismos.

En tal sentido, el desafío de atender el problema de la salud mental luego de los terremotos ha encontrado rápidamente serios obstáculos. Por un lado, ha debido enfrentar una cosmovisión mágica y fatalista de la realidad, en la cual predominan los mitos y las histerias sociales, generadas por la incertidumbre y la falta de explicaciones satisfactorias a los fenómenos naturales. La multiplicación de rumores, que anunciaban la destrucción total del país en ciertas fechas y el consecuente comportamiento de muchas personas en respuesta a los mismos, es un ejemplo claro de ella. En estas circunstancias, la disponibilidad de la gente para recuperar o crear los mecanismos que le ayuden a reconstruir su entorno psicosocial es muy limitada. La gente está más preocupada por interpretar las supuestas señales divinas y saber si está incluida en algún plan de salvación milagrosa frente al desastre que por trabajar conjuntamente con sus pares para prevenir fuluras desgracias y reconstruir las condiciones básicas de supervivencia digna. Al final de cuentas, si el futuro ya está escrito y su nombre es fatalidad, sólo queda esperarlo y conseguir la mejor comunicación con la deidad responsable. Pero los obstáculos al trabajo de salud psicosocial no sólo radican en esa cosmovisión presente entre varios ciudadanos. Dicho trabajo ha debido lidiar con la moda más o menos lácila de entender la atención en salud mental como una serie de técnicas y herramientas de relajación, que reducen la aproximación a lo psicológico al mejor estilo de las dosis recetadas en el entorno médico. El excesivo énfasis en el marco explicatorio que provec la corriente adscrita al Síndrome de Estrés Postraumático (Post-Traumatic Stress Disorder), por lo general no hace sino descontextualizar el hecho de que la mayor parte de la gente ha sido víctima de un desastre más en una larga cadena de adversidades sociales, económicas y ambientales. Aunque no se puede negar la importancia explicativa de marcos teóricos o herramientas como ésas y su utilidad a la hora de sacar a las personas de las crisis explosivas provocadas por las tragedias, la verdad es que esta perspectiva ha impedido que grupos importantes de profesionales vuelvan su mirada al trabajo comunitario de reconstrucción como una herramienta de elevado valor psicoterapéutico. La aparente moda de entender la atención en salud mental como la capacidad de disponer de habilidades para la atención en crisis estaría minando la capacidad de ver a los recientes terremotos como una oportunidad para devolver el poder terapéutico a la gente de trabajar activamente por su entorno y mejorarlo, inclusive más allá de las limilaciones individuales.

De ahí que a pesar de que la emergencia impone la necesidad de contar con respuestas rápidas y efectivas en el ámbito de la atención primaria en salud mental, sobre todo con aquellos cuadros psicológicos más graves, esto no debe desviar la 
atención y las estrategias de trabajo de las inveleradas necesidades de supervivencia social de los ciudadanos y que continuarán ahí aún después del fin de la emergencia. Esto sólo puede lograrse desde la atención en salud psicosocial, entendida como un proceso de reestructuración y fortalecimiento de las relaciones sociales y comunitarias, en un marco de convivencia pacifica y solidaria, que provea recursos para el desarrollo y la construcción de condiciones de vida más justas y dignas para los supervivientes de los continuos desastres socionaturales, que marcan la vida en este agilado país.

José Miguel Cruz

Director del Instituto Universitario de Opinión Pública de la UCA 